\title{
絭 \\ Some physical and chemical characteristics of calcium lignosulphonate-bound coal fines
}

\author{
by C.A. Strydom*, T.S. Mthombo*, J.R. Bunt ${ }^{\dagger}$, and \\ H.W.J.P. Neomagus ${ }^{\dagger}$
}

\section{Synopsis}

Low-cost calcium lignosulphonate (CL), which is a byproduct of the wood pulping industry, was investigated as a potential binder during laboratoryscale pelletization of inertinite-rich high-ash coal fines from the Highveld Coalfield of South Africa. Coal-binder mixtures containing between 1 and $15 \%$ calcium lignosulphonate were prepared, pressed, and ultimate, proximate, porosity, XRD, and XRF analyses obtained. It was found that increased pressure during pelletization results in increased attractive forces, due to increased interparticle contact areas. FTIR analysis showed that chemical interactions occur between coal fines and the binder, as evidenced by the formation of new $\mathrm{C}-\mathrm{O}$ ether-type bonds. The presence of moisture during pelletization enhanced surfactant activity of the binder. Chemical interactions between the coal and the binder seem to be mainly electrostatic, driven by $\mathrm{Ca}^{2}+$ from the calcium lignosulphonate, which may act as a bridge between the anionic parts of the binder and the surface of the coal.

\section{Keywords}

Calcium lignosulphonate, coal fines, chemical interaction, binder, surfactant, porosity.
Consequently, utilization of these coal fines is an area of great interest. Mechanical densification of fine coal by means of pelletization and/or briquetting to larger sizes for use in technologies that require lump coal, such as chain-grate stokers and fixed-bed gasifiers, has been shown not only to reduce environmental risks (Mangena et al., 2004), but also to significantly reduce storage and transportation costs (Mani et al., 2001). Pelletization is the process by which solid particles are consolidated into uniform, usually hard, impact-resistant agglomerates, rendering them useful as a fuel with sufficient calorific value for domestic and industrial utilization (Finney, Sharifi, and Swithenbank, 2009).

Coal can be agglomerated either with or without the use of a binder. Although binderless pelletization is the cheapest, and often the preferred, form of pelletizing (due to the elimination of binder costs), it is not always effective. Conventional binderless pelletization may not always yield the desired specific properties such as water resistance, combustion characteristics, durability, etc. The addition of a binder, on the other hand, enhances agglomeration properties, thereby reducing the intensity of pelletizing conditions such as high temperature and pressure. In this study, an organic binder, lignin sulphonate (lignosulphonate), was used as a binding agent in the production of pellets from coal fines.

Lignosulphonate $\left(\mathrm{C}_{20} \mathrm{H}_{24} \mathrm{RO}_{10} \mathrm{~S}_{2}\right)$ is a cellulose-based organic component of trees that is obtained as a byproduct of the paper industry. During sulphite pulping, acidic

* Chemical Resource Beneficiation (CRB). NorthWest University, South Africa.

+ Unit for Energy and Technology Systems. School of Chemical and Minerals Engineering, NorthWest University, South Africa.

(c) The Southern African Institute of Mining and Metallurgy, 2018. ISSN 2225-6253. Paper received Nov. 2017; revised paper received Mar. 2018. 


\section{Some physical and chemical characteristics of calcium lignosulphonate-bound coal fines}

cleavage of ether bonds on the $\alpha$-carbon of the propyl sidechain in lignin results in the formation of electrophilic carbocations, which in turn react with bisulphite ions $\left(\mathrm{HSO}_{3}{ }^{-}\right)$, to produce sulphonates (Stuart, Jerry, and Timothy, 2001). Primarily, lignosulphonates are recovered from the pulping liquid through the Harvard process, in which up to a $95 \%$ yield of calcium lignosulphonate $\left(\mathrm{C}_{20} \mathrm{H}_{24} \mathrm{RO}_{10} \mathrm{~S}_{2}\right)$ is precipitated in excess calcium hydroxide. Figure 1 shows the typical unit structure of calcium lignosulphonate.

The lignosulphonate part of calcium lignosulphonate (CL) may behave as an anionic surfactant, containing both hydrophilic (e.g. sulphonic, phenolic hydroxyl) and hydrophobic (i.e. carbon chain) groups, and thus possesses a certain degree of surface activity (Fredheim, Christensen, and Bjørn, 2003; Chen and Wu 1994). It has been used as an adhesive (Chen and $\mathrm{Wu}$ 1994), as well as an auxiliary substance for paper coating (Telysheva, Dizhbite, and Paegle, 2001). More than $50 \mathrm{Mt}$ of lignin (lignosulphonate plus alkali lignin) are globally produced annually, of which only $10 \%$ is utilized (Xiao, Sun, and Sun, 2001). The unused lignosulphonate needs to be treated in order to alleviate environmental risks, which is an undesirable expenditure.

Previous research focused on binderless briquetting of vitrinite-rich coal fines, and investigations into the agglomeration of inertinite-rich coals has received less attention (Finney, Sharifi, and Swithenbank, 2009). Leokaoke et al. (2018) studied the manufacturing and testing of briquettes from inertinite-rich low-grade coal fines using various binders. They reported that the use of lignosulphonate as a binder resulted in briquettes with sufficient compression strength to be considered for industrial application. Emphasis has been on the physical properties of the manufactured pellets, with little interest in understanding the mechanisms of binding. In this paper we describe the characterization of the more physico-chemical properties of fine inertinite-rich coal pellets with calcium lignosulphonate as a binding agent. The pellets were prepared in the manner described by Leokaoke et al. (2018). The mechanism by which the binding occurs is investigated and reported on.

Finney, Sharifi, and Swithenbank (2009) compared inorganic (caustic soda) and organic (starch) binders for the preparation of coal tailings pellets. They concluded that an

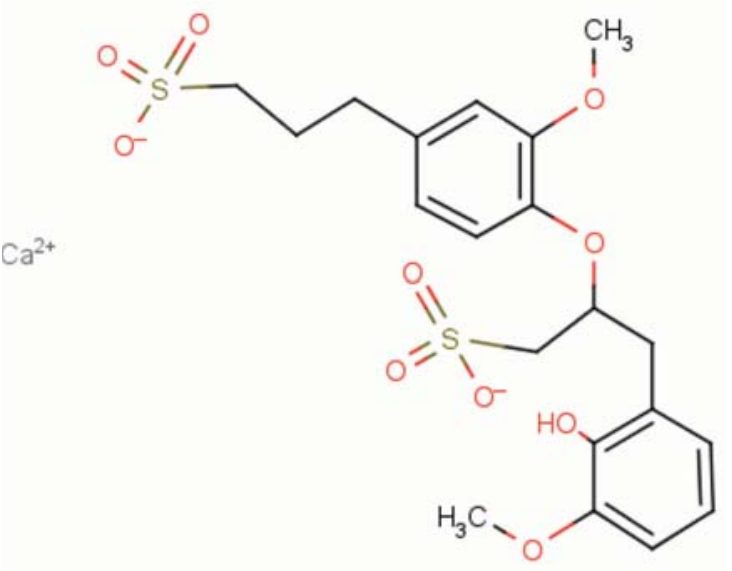

Figure 1-Typical structural unit of calcium lignosulphonate addition of $2 \%$ of starch binder improved the pellet quality. They attributed this to the inherent lignin in the starch, which softened, especially at elevated temperatures (45$75^{\circ} \mathrm{C}$ ), thus enhancing agglomeration. Zhang et al. (2001) investigated the effect of different treatment conditions on rice straw-based binders in lignite coal briquettes. They found that sodium hydroxide-treated rice straw can be used as a lignite briquette binder.

Chung (1991) reviewed several adhesion theories and concluded that at the microscopic level, the driving force of adhesion is the electrostatic interactions between molecules. The binding forces between the particles can exist with or without a chemical bond (covalent bond) being formed (Rumpf, 1962). In the absence of covalent bonds, attraction between particles is due to forces such as molecular interactions (hydrogen bonds, van der Waals attraction etc.) and electrostatic and magnetic forces, provided the particles are brought close enough together (Rumpf 1962). Van der Waals forces are believed to make the largest contribution of all intermolecular attractive effects, while electrostatic forces help binding where there is an excess charge or electrical charged surface, which may be created by interparticle friction (Zhou, Zhu, and Wang, 2004). Covalent bonds, on the other hand, may form via reactions between molecules in particles from different parts of the mixture at points of contact (Kaliyan and Morey 2010), especially under applied pressure.

\section{Materials and methods}

\section{Materials}

A batch of the same South African medium-rank, low-grade, inertinite-rich discard coal from the Highveld Coalfield used by Leokaoke et al. (2018) was obtained. Calcium lignosulphonate powder was used as supplied by a local pulping company.

\section{Coal and binder characterization}

\section{Coal petrography}

A suitably prepared representative portion of the coal sample (fines) was set in an epoxy and resin mixture, and then ground to a polished surface for microscopic investigation, according to the standard methods for petrographic analysis. Maceral analysis was conducted using a Zeiss Axio imager at 500x magnification under oil immersion. Petrographic analyses were done according to ISO 7404:1994 to obtain vitrinite reflectance and maceral composition.

\section{Proximate and ultimate analysis}

Proximate analyses were performed using the following standard methods: moisture - ISO 11722: 1999; ash content - ISO 1171: 2010; volatile matter content - ISO 562: 2010; and fixed carbon content was determined by difference. Ultimate analyses (carbon, hydrogen, nitrogen, and sulphur weight percentages) were based on the ISO 29542: 2010 method and were performed by Bureau Veritas Testing and Inspections, South Africa. The total sulphur content was determined according to ISO 19759: 2006 using IR spectroscopy. For comparison, pellets manufactured from the coal and specified binder concentrations (wt.\%) were also analysed for their proximate and ultimate compositions. 


\section{Some physical and chemical characteristics of calcium lignosulphonate-bound coal fines}

\section{Mineralogical analysis}

Coal fines, calcium lignosulphonate, and the produced pellets were subjected to mineralogical analysis using X-ray diffraction (XRD) with a PANalytical V4.1 instrument, utilizing the Rietveld-based X'Pert HighScore Plus software to identify and semi-quantify minerals. Samples were fused into a borosilicate disk and analysed by X-ray fluorescence (XRF) spectrometry at Set Point Laboratories, South Africa.

\section{Density and porosity}

To characterize the structural properties of the coal and CL binder material before and after pellet preparation, density and porosity measurements were carried out. The sample masses were measured using an electronic balance with an accuracy of $10^{-4} \mathrm{~g}$. The bulk density was determined using the equation:

$$
\rho_{\mathrm{b}}=\frac{m}{v_{\mathrm{b}}}
$$

where $\rho_{b}\left(\mathrm{~g} \mathrm{~cm}^{-3}\right)$ is the bulk density, $m$ is the mass $(\mathrm{g})$, and $v_{\mathrm{b}}$ is the bulk volume.

True volumes of the samples, were estimated using a helium stereo pycnometer (Quantachrome, MVP-1) with an accuracy of $0.001 \mathrm{~cm}^{3}$. The procedure involved degassing the sample by purging with a flow of dry helium. The analysis is performed by pressurizing the sample cell, then expanding the gas into a reference chamber. The sample volume is calculated from the two pressure readings. Three measurements were performed, the averages for each sample were obtained, and the density was calculated by the equation:

$$
\rho_{\mathrm{t}}=\frac{m}{v_{\mathrm{t}}}
$$

where $\rho_{\mathrm{t}}\left(\mathrm{g} \mathrm{cm}^{-3}\right)$ is the true density, $m$ is the mass $(\mathrm{g})$, and $v_{\mathrm{t}}$ is the true volume.

The porosity $(\varepsilon)$ was estimated from Equations [1] and [2] using the relationship

$$
\varepsilon=1-\frac{\rho_{\mathrm{b}}}{\rho_{t}}
$$

\section{Pellet preparation}

Inertinite-rich coal fines were air-dried under ambient conditions for 24 hours, then pulverized to pass $250 \mu \mathrm{m}$ using a Fritsch pulverisette (Labotec, South Africa). The pulverized coal fines were mixed with the desired amount of binder using an overhead stirrer (Heidolph RZR 2041) at a constant speed of $20 \mathrm{r} / \mathrm{min}$ for 1 hour. Coal-binder mixtures containing between 1 and 15\% calcium lignosulphonate were prepared. The coal-binder mixtures were then pressed using an LRX Plus tensile test machine (Ametek Lloyd Instruments). The procedure involved weighing $2.5 \mathrm{~g} \pm$ $0.0005 \mathrm{~g}$ of the mixture into a cylindrical, $13 \mathrm{~mm}$ internal diameter die set. The mixture was then compressed into a small pellet with a force of $4000 \mathrm{~N}$ at a rate of $10 \mathrm{~mm} / \mathrm{min}$ and holding time of 10 seconds after reaching the maximum force. The pressed pellets were stored in a closed container prior to analysis.

\section{Pellet analyses}

\section{Surface morphology}

Surface morphology studies of coal and binder samples were carried out on as-received samples, while for the pellets, the cross-sectional surfaces were analysed. Samples were observed under an FEI Quanta 200 scanning electron microscope (SEM) with an integrated Oxford Instruments INCA 200 energy-dispersive X-ray spectroscopy (EDS) microanalysis system, at an accelerating voltage of $5 \mathrm{kV}$. Samples were mounted on double-sided adhesive tape, and then coated with a gold-palladium coating under a $4.0 \mathrm{~Pa}$ vacuum to render them conductive. Images of each sample were taken at low $(600 x)$ and high $(2400 x)$ magnifications.

\section{Chemical composition}

Fourier transform infrared (FT-IR) analysis was performed using a Perkin Elmer Spectrum 400 FT-IR/FT-NIR equipped with a universal Attenuated Total Reflectance (ATR) sampling accessory to determine the differences in the functional groups in the samples before and after pelletizing. Approximately $1 \mathrm{mg}$ of each sample was placed on a sample holding hole, and pressed by means of a gauge force arm mounted on top of the instrument in order to ensure maximum contact with the detector. Spectra of all three samples were recorded in the range 1800 to $600 \mathrm{~cm}^{-1}$.

\section{$\mathrm{pH}$ and zeta potential measurements}

Samples were prepared by dispersing a pellet in $50 \mathrm{ml}$ deionized water and stirring the mixture for approximately 5 minutes using a magnetic stirrer. The same procedure was followed for $2.5 \mathrm{~g}$ coal and $2.5 \mathrm{~g}$ calcium lignosulphonate, and the samples' pH changes were measured between 3 and 30 minutes. In order to determine the adsorption behaviour of the calcium lignosulphonate particles on the coal surface, zeta potential measurements were carried out using a Zetasizer Nano ZS (Malvern, South Africa). The prepared pellet in the deionized water sample was transferred into a clear, disposable, electrophoretic cell for analysis. The procedure was repeated five times and the mean value reported. The temperature was set at room temperature.

\section{Results and discussion}

\section{Coal petrography}

Results of the petrographic analysis of the fine coal sample are given in Table I. The vitrinite content was found to be 28.1 vol.\%. The medium-rank $\mathrm{C}$ bituminous coal contains 56.2 vo.1\% inertinite. Mineral matter was determined as 9.4 vol.\%.

\section{Table I}

\section{Petrographic analysis of the coal fines (m.m.b.)}

\begin{tabular}{|l|c|}
\hline Marceral composition (m.m.b.) & vol. \% \\
\hline Vitrinite & 28.1 \\
Liptinite & 0.0 \\
Inertinite & 56.2 \\
Fusinite + secretinite & 6.3 \\
Mineral matter & 9.4 \\
\hline Rank & Bituminous medium- \\
& rank C \\
\hline
\end{tabular}




\section{Some physical and chemical characteristics of calcium lignosulphonate-bound coal fines}

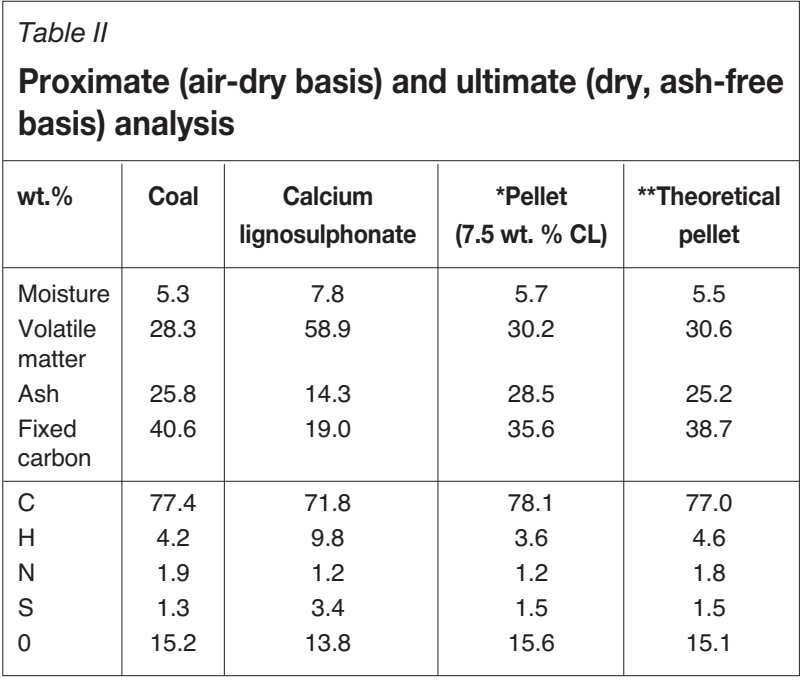

*Pellet composition: 7.5 wt.\% calcium lignosulphonate ** Theoretical pellet: $\Sigma(92.5 \%$ coal $+7.5 \% \mathrm{CL})$

\section{Proximate and ultimate analyses}

Results of the bulk proximate (air-dried basis) and ultimate (dry, ash-free basis) analyses are given in Table II. For comparisons theoretical values for the pellet are also listed. The proximate and ultimate analyses results for the $7.5 \mathrm{wt} . \%$ CL-coal pellet were similar to that of the coal fines.

\section{Mineralogical analyses}

XRF results for the coal fines, calcium lignosulphonate, and pellet ( $7.5 \mathrm{wt} . \% \mathrm{CL}$-coal) are given in Table III. The XRF analysis was used to determine the sulphur content $\mathrm{as}_{3}$ in the pressed pellets. Calcium lignosulphonate is characterized as a sample containing higher $\mathrm{CaO}$ and $\mathrm{SO}_{3}$ contents than the coal fines. As expected, the three samples analysed have high LOI values (77.2-86.4\%), reflecting mostly the remaining ash content.

XRD results for the coal fines sample (Figure 2) provide an indication of the concentrations of crystalline minerals. The crystalline minerals comprise mainly kaolinite (9.3\%), illite $(2.8 \%)$, quartz $(3.5 \%)$, and gypsum $(1.1 \%)$ with minor
Table III

XRF analysis (wt. \%) of calcium lignosulphonate

(CL), coal fines, and pellet (7.5 wt. \% CL)

\begin{tabular}{|l|c|c|c|}
\hline & Coal fines & CL & $\begin{array}{c}7.5 \text { wt. } \% \text { CL } \\
\text { pellet }\end{array}$ \\
\hline $\mathrm{Fe}_{2} \mathrm{O}_{3}$ & 1.3 & 0.06 & 0.6 \\
$\mathrm{MnO}$ & $<0.1$ & $<0.1$ & $<0.1$ \\
$\mathrm{CaO}$ & 1.5 & 8.5 & 2.6 \\
$\mathrm{~K}_{2} \mathrm{O}$ & 0.3 & 0.2 & 0.4 \\
$\mathrm{SiO}_{2}$ & 11.4 & 0.8 & 6.8 \\
$\mathrm{Al}_{2} \mathrm{O}_{3}$ & 5.7 & 0.2 & 2.8 \\
$\mathrm{MgO}$ & 0.4 & 0.3 & 0.3 \\
$\mathrm{Na}_{2} \mathrm{O}$ & 0.1 & 0.1 & 0.1 \\
$\mathrm{SO}_{3}$ & 3.2 & 7.0 & 8.6 \\
\hline $\mathrm{LOI}^{*}$ & 77.2 & 86.1 & 82.7 \\
\hline
\end{tabular}

$\mathrm{LOI}^{*}=$ loss on ignition

goyazite and calcite. Similar results were observed for pellets with between 1 and 15\%. CL binder. Matjie, Ward, and Li (2012) reported that South African Highveld coals contain abundant kaolinite and quartz, with minor illite, calcite, pyrite, dolomite, goyazite, and gypsum. Significant concentrations of kaolinite and illite clay minerals, which are more reactive than other coal minerals, were also found. The XRD analysis of the calcium lignosulphonate sample (Figure 2) indicates that this sample contains noncrystalline phases. Pelletization thus does not seem to influence the mineral matter composition.

\section{Surface morphology, density, and porosity}

SEM images of the surface morphology of the coal and calcium lignosulphonate particles, as well as images of crosssectional surfaces of the pellets, are shown in Figure 3. Unlike the calcium lignosulphonate particles, the coal fines particles are sharper-edged, with finer particles that are more compacted (Figure $3 \mathrm{a}$ and $3 \mathrm{~b}$ ). A comparison of the pellet with $2.5 \%$ CL binder (Figure $3 \mathrm{c}$ ) and that with $7.5 \%$ binder

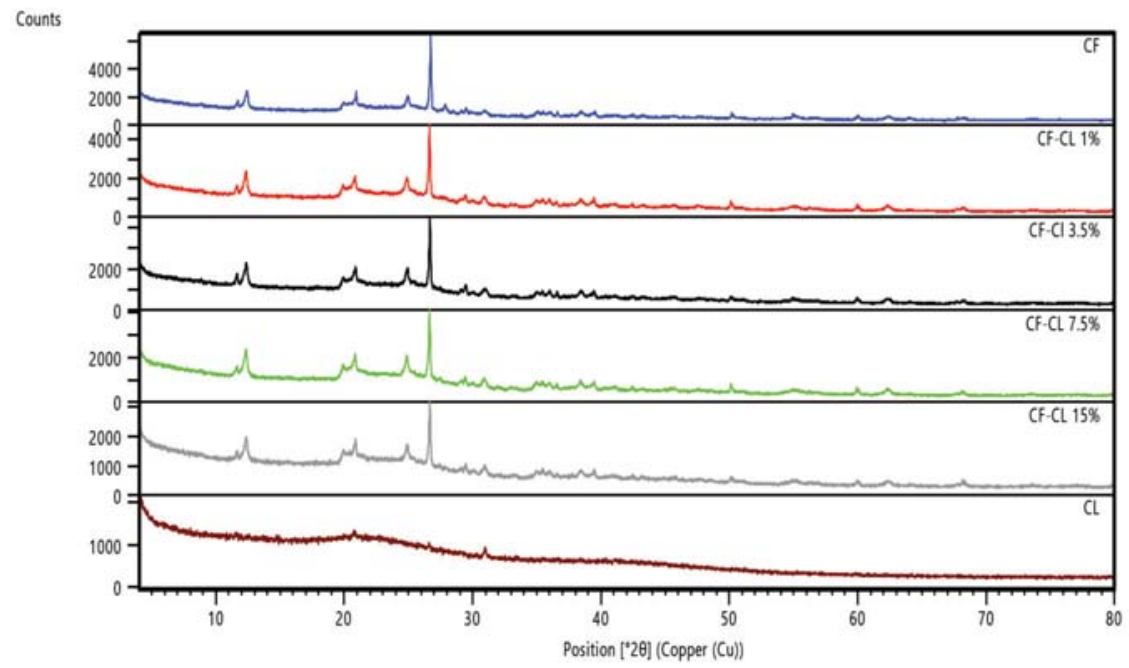

Figure 2-XRD diffractograms of coal fines (CF), calcium lignosulpfonate (CL), and pellets (CF-CL) with varying CL content (wt.\%) 


\section{Some physical and chemical characteristics of calcium lignosulphonate-bound coal fines}
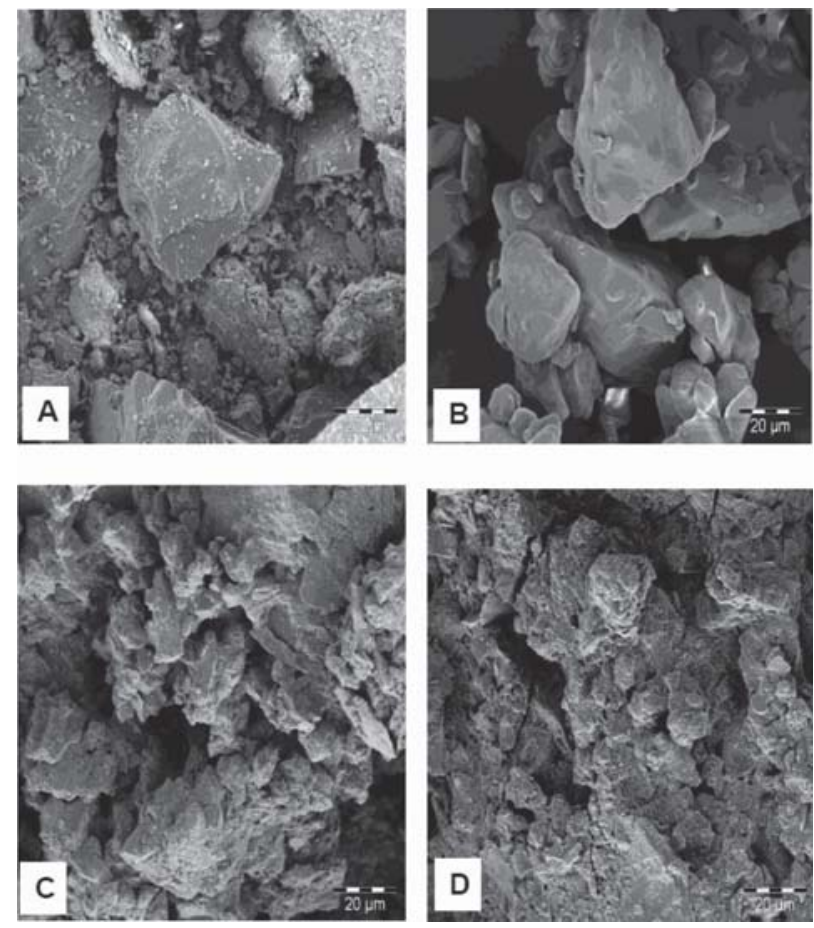

Figure 3-SEM images (2400x magnification) of (a) coal fines, (b) calcium lignosulphonate $(\mathrm{CL})$ binder, cross-sectional areas of fractured coal fines pellets with (c) $2.5 \mathrm{wt} . \% \mathrm{CL}$, and (d) with $7.5 \mathrm{wt} . \% \mathrm{CL}$

(Figure 3d) shows an increase in compactness of the pellets with increased binder dosage. A decrease in the voids between the coal and binder particles is thus expected.

During the initial stages of pelletization, i.e. at low pressures, it is commonly considered that some sliding, rearrangement, and/or fragmentation of the particles may occur, resulting in a more closely packed structure, and hence a decrease in voidage (Mani et al., 2001). Furthermore, since during pelletization the loading is hydraulic in nature, the application of pressure may fragment brittle particles. Increased pressure will result in the elastic (temporary) or plastic (permanent) deformation of particles, which significantly increases the interparticle contact area and may result in attraction between the molecules in adjacent particles. The initial interparticle attraction is due to weak van der Waals and electrostatic forces. The porosity of the coal fines sample was determined to be 0.688 , that of the calcium lignosulfonate sample 0.397 , and that of the 7.5 wt.\% CL-coal pellet 0.325 . A clear reduction in porosity for the pellet indicates closer contact between all samples on a structural level. An additional strength-enhancing result of the compression process may be that flat-shaped particles and bulky particles may mechanically interlock (Rumpf, 1962).

\section{FTIR spectroscopy}

Infrared spectroscopic spectra of the calcium lignosulphonate, coal, and a pellet with $7.5 \%$ binder disclose the differences in chemical composition (Figure 4). The FTIR spectra reveal that some chemical differences exist between the pellet and the starting materials.

Only the main differences in the spectra are described. The peak band at $1600 \mathrm{~cm}^{-1}$ represents $\mathrm{C}=\mathrm{C}$ stretching of aromatic rings (Shen, Zhang, and Zhu, 2008). A shoulder on the peaks for the coal and pellet at approximately $1650 \mathrm{~cm}^{-1}$ is assigned to $\mathrm{C}=\mathrm{O}$ stretching vibrations, with no shoulder observed for the CL sample. Peaks observed in the region between 1300 and $1110 \mathrm{~cm}^{-1}$ may be due to the presence of ether groups, $\mathrm{C}-\mathrm{O}$ stretching, and $\mathrm{O}-\mathrm{H}$ bending vibrations (Shen, Zhang, and Zhu, 2008). The distinct peak at 1221 $\mathrm{cm}^{-1}$ for the pellet sample may indicate the formation of additional ether-type groups.

The major peaks at $1032 \mathrm{~cm}^{-1}$ denote the aromatic skeletal and sulphonic groups, and are characteristic of the sulphonic group present in the calcium lignosulphonate binder (Shen, Zhang, and Zhu, 2008).

\section{Zeta potential}

The zeta potential of a dispersion of calcium lignosulphonate in deionized water was found to average $-20 \mathrm{mV}$. As seen in Figure 5, zeta potential (in absolute value) of coal pellets containing CL increases with increasing CL concentration up to approximately $4 \mathrm{wt} . \%$. The zeta potential of the pellet initially becomes more negative with the addition of the binder, indicating interaction between the coal fines and the binder. This observation is consistent with results from a mechanical study in which maximum compression strength was observed for pellets with $4 \mathrm{wt}$.\% CL as binder (Leokaoke et al., 2018).

Proximate analysis indicated that the air-dried coal pellets contained approximately $6 \%$ moisture (Table I). The moisture on the surface of the pellets will dissolve soluble constituents of the coal fines and the calcium lignosulphonate binder, with resulting acid or basic properties at the surfaces. The surface acidity or basicity was simulated by preparing mixtures of the $7.5 \mathrm{wt} . \% \mathrm{CL}$-coal pellet, calcium lignosulphonate, and coal fines in deionized water and measuring the $\mathrm{pH}$. The changes in the $\mathrm{pH}$ value for the three samples with time are shown in Figure 6 . The coal fines mixture yielded $\mathrm{pH}$ values between 7.6 and 8.2, producing basic solutions. The $\mathrm{pH}$ values for the calcium lignosulphonate mixture were in the acidic region, between

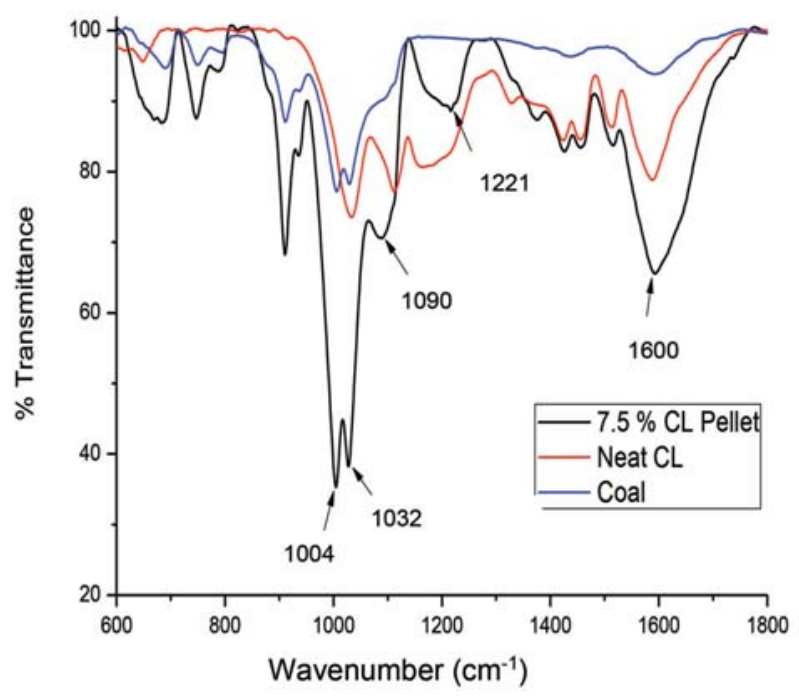

Figure 4-FTIR spectra of starting components and pellet containing 7.5 wt. \% calcium lignosulphonate 


\section{Some physical and chemical characteristics of calcium lignosulphonate-bound coal fines}

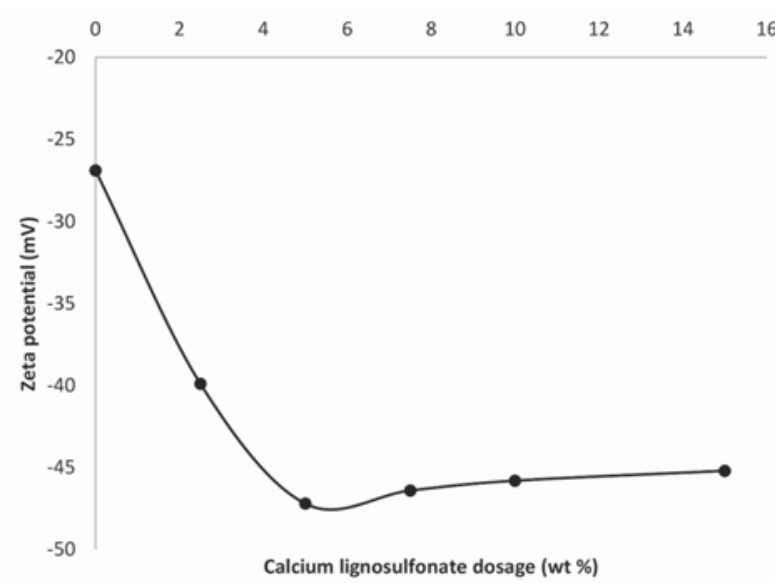

Figure 5-Zeta potential curve of calcium lignosulphonate coal pellets dispersed in deionized water

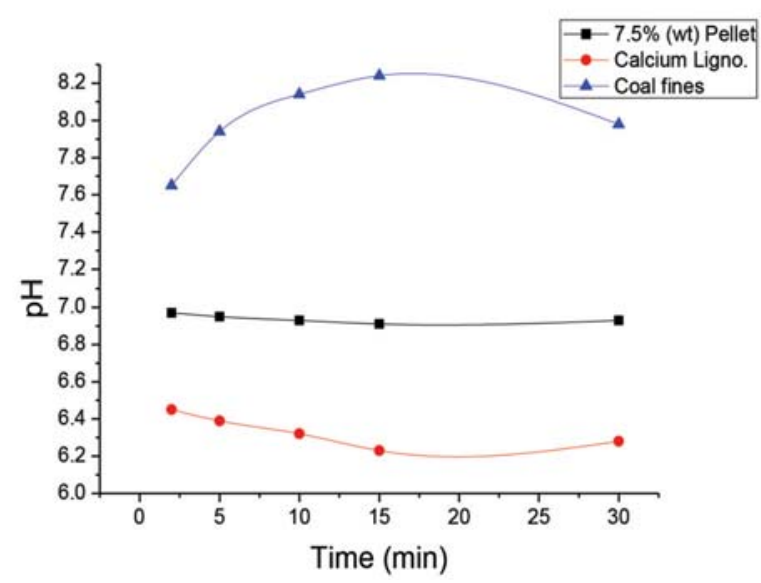

Figure 6-pH measurements of aqueous mixtures of coal, calcium lignosulphonate, and a pellet $(7.5 \% \mathrm{CL})$ as a function of time

6.4 and 6.2. The pellet mixture gave close to neutral $\mathrm{pH}$ values between 6.9 and 7.0. The difference in the $\mathrm{pH}$ values between the coal fines sample, the binder, and the pellet indicates that the interaction between the binder and the coal fines may be between acidic and basic ions in the moisture and on the surfaces of the two components of the pellet.

\section{Interaction between binder and coal fines}

In an attempt to characterize the interactions that occur between the calcium lignosulphonate binder and the coal fines, both microscopic and macroscopic approaches were used. It is postulated that the interactions between the coal particles and calcium lignosulphonate in the pellet occur not only through mechanical processes (Rumpf, 1962), but also through the surfactant activity of the polymeric calcium lignosulphonate and the coal surface (Ogura, Tanoura, and Hiraki, 1993).

The application of high pressure during pelletization brought particles closer together, and the increased interparticle contact enhanced interparticle attraction forces between adjacent particles through weak van der Waals forces (Rumpf, 1962). During this process, deformation of particles results in smaller particles filling the voids between larger particles, which may bring about mechanical interlocking between adjacent particles.

Furthermore, the presence of moisture enhances surfactant activity. Lignosulphonates may act as surfactant molecules with spherical structures (micelles), where the sulphonic acid and carboxylic acid groups are positioned mainly at the surface of a hydrophobic hydrocarbon core (Rezanowich and Goring, 1960; Le Bell, 1984). These functional groups are therefore accessible for interactions, especially when surface moisture is present.

FTIR spectroscopy demonstrated that the chemical structure in the pellet was slightly altered during mixing and pelletization, with the formation of additional $\mathrm{C}-\mathrm{O}$ ether bonds.

The combination of $\mathrm{pH}, \mathrm{XRD}, \mathrm{XRF}$, and zeta potential measurements with the FTIR analyses has provided an improved basis for understanding the interactions between the coal surface and the CL binder during pelletization. Generally, poly-anions such as lignosulphonate groups tend to be repelled from the already negatively-charged coal surface. In such instances, adsorption and bonding is promoted by the presence of polyvalent cations, which act as bridges between the anionic groups of the surfactant and the negatively charged sites on the coal. Thus, as demonstrated in Figure 7, calcium ions share positive charges, resulting in the formation of ionic or electrostatic bonds between the sulphonyl groups in the binder and negatively charged sites on the coal surface, and possible ether sites as an increase in the ether $(\mathrm{C}-\mathrm{O})$ vibrations is observed on the FTIR spectra. The interactions between the lignosulphonate groups and the coal surface will also render the surface less available for basic or acidic interaction with surface water. This is evident from the almost neutral $\mathrm{pH}$ observed when the pellet is mixed with water.

\section{Conclusion}

The physico-chemical properties that influence the binding mechanisms between inertinite-rich high-ash coal fines and a calcium lignosulphonate binder were investigated. Microstructural analysis of the pellets suggests that the physical interactions between the coal and binder result in a decrease in the voids between particles, and thus an increase

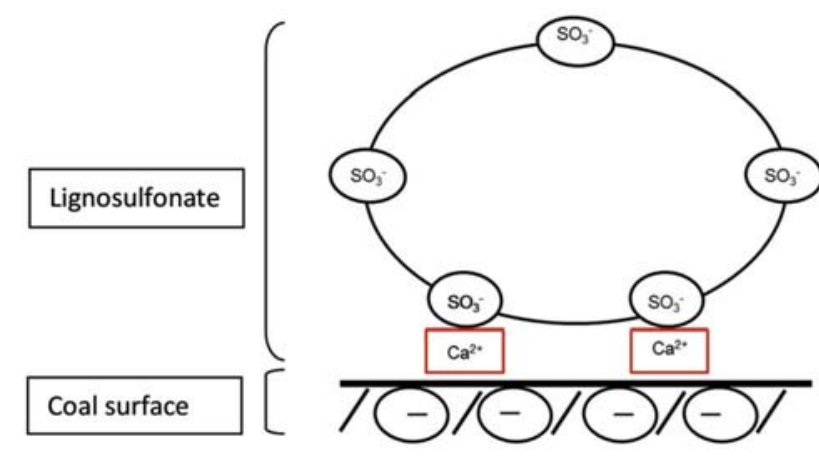

Figure 7-Schematic diagram showing the role of calcium ions in the adsorption of calcium lignosulphonate onto the coal surface 


\section{Some physical and chemical characteristics of calcium lignosulphonate-bound coal fines}

in interparticle contact area. This enhances binding through attractive forces, with van der Waals forces believed to make the biggest initial contribution.

Chemical analysis confirmed that not only physical, but also chemical, interactions occur during and/or after mixing and pelletization. Chemical interactions, whereby new ether $\mathrm{C}-\mathrm{O}$ bonds are formed between coal fines and the binder, are evident from FTIR analysis. Zeta potential investigations indicate that chemical adsorption through electrostatic attraction is one of the pathways through which binding occurs. Increasing the binder dosage in a pellet increases the sulphonic group concentration, and hence increases the charge density, which results in an increase in zeta potential until a maximum effect is obtained at approximately 4\% CL addition to coal fines

In order to utilize calcium lignosulphonate as a binder for high-ash inertinite-rich coal fines, the fate of the sulphur in the pellet and during thermal treatment should be known. Investigation of the interaction between the minerals and calcium lignosulphonate at elevated temperatures is planned, in an attempt to determine the fate of the sulphur, and to propose mechanisms to deal with possible gaseous sulphur emissions.

\section{Acknowledgments}

The authors acknowledge the North-West University's Chemical Resource Beneficiation (CRB) research focus area and the Technology Innovation Agency (TIA - SF1601001) for financial support for this study. This work is based on the research supported by the South African Research Chairs Initiative of the Department of Science and Technology and National Research Foundation of South Africa (Coal Research Chair Grant No. 86880, UID85643, and UID85632). Any opinion, finding, or conclusion or recommendation expressed in this material is that of the authors and the NRF does not accept any liability in this regard.

\section{References}

Arndt, C., Davies, R., Gabriel, S., Makrelov, K., Merven, B., Hartley, F., and ThurLow, J. 2016. A sequential approach to integrated energy modeling in South Africa. Applied Energy, vol. 161. pp. 591-599.

CHEN, R. and Wu, Q. 1994. Modified lignosulfonate as adhesive. Journal of Applied Polymer Science, vol. 52. pp. 437-443.

Chung, F.H. 1991. Unified theory and guidelines on adhesion. Journal of Applied Polymer Science, vol. 42, no. 5. pp. 1319-1331.

Clausen, H.T. 1973. Ecological aspects of slimes-dam construction. Journal of the South African Institute of Mining and Metallurgy, vol. 74, no. 5. pp. 178-183.

FinNey, K.N., SHARIFI, V.N., and SwithEnBAnK, J. 2009. Fuel pelletisation with a binder: Part I - Identification of a suitable binder for spent mushroom compost-coal tailing pellets. Energy and Fuels, vol. 23. pp. 3195-3202.

Fredheim, G.E., Christensen, C., and BjøRn, E. 2003. Polyelectrolyte complexes: interactions between lignosulfonate and chitosan. Biomacromolecules, vol. 4. pp. 232-239.

ISO (International Organization for Standardization). 1994. ISO 7404-3: 1994 and ISO 7404-5: 1994 Methods for the petrographic analysis of bituminous coal and anthracite. Geneva.

ISO (International Organization for Standardization). 2006. ISO19579: 2006 Determination of total sulphur through IR spectroscopy. Geneva.

ISO (International Organization for Standardization). 2010a. ISO 11722: 2010.
Solid mineral fuels - hard coal - determination of moisture in the general analysis test sample by drying in nitrogen. Geneva.

ISO (International Organization for Standardization). 2010b. ISO1171: 2010. Solid mineral fuels - Determination of ash. Geneva.

ISO (International Organization for Standardization). 2010c. ISO 562: 2010. Hard coal and coke - Determination of volatile matter. Geneva.

ISO (International Organization for Standardization). 2010d ISO 29541: 2010. Determination of total carbon, hydrogen and nitrogen - instrumental method. Geneva.

Kaliyan, N. and MoRey, R.V. 2010. Natural binders and solid bridge type binding mechanisms in briquettes and pellets made from corn stover and switchgrass. Bioresource Technology, vol. 101. pp. 1082-1090.

LE BELL, J.C. 1984. The relation between the structure of lignosulphonates and their effect as stabilizers for latex particulate dispersions. Colloids and Surfaces, vol. 9, no. 3. pp. 237-251.

Le Roux, M., CAMPBELL, Q.P., and Smit, W. 2012. Large-scale design and testing of an improved fine coal de-watering system. Journal of the Southern African Institute of Mining and Metallurgy, vol. 112. pp. 673-676.

LeoKaoke, N.T., Bunt, J.R., Neomagus, H.W.J.P., WAanders, F.B., Strydom, C.A., and Мтномво, T.S. 2018. Manufacturing and testing of briquettes from inertinite-rich low-grade coal fines using various binders. Journal of the Southern African Institute of Mining and Metallurgy, vol. 118. pp. 83-88.

Mangena, S.J., De KoRTe, G.J., McCrindle, R.I., and Morgan, D.L. 2004. The amenability of some Witbank bituminous ultrafine coals to binderless briquetting. Fuel Processing Technology, vol. 85. pp. 1647-1662.

Mani, S., SoKhansanj, S., BI, X., and Turhollow, A. 2001. Economics of producing fuel pellets from biomass. Applied Engineering Agriculture, vol. 22. pp. 421-426.

MATJIE, R.H., WARD, C.R., and LI, Z. 2012. Mineralogical transformations in coal feedstocks during carbon conversion, based on packed bed combustor tests, Part 1: Bulk coal ash studies. Coal Combustion and Gasification Products, vol. 4. pp. 45-54.

Ogura, T., TANoura, M., and Hiraki, A. 1993. Behaviour of surfactants in a highly loaded coal-water slurry: effect of surfactant concentration on its properties. Bulletin of the Chemical Society of Japan, vol. 66. pp. 1343-1349.

RAdLofF, B., KiRSTEN, M., and Anderson, R. 2003. Wallerawang Colliery rehabilitation: the coal tailings briquetting process. Minerals Engineering, vol. 17. pp. 153-157.

ReZanowich, A. and Goring, D.A.I. 1960. Polyelectrolyte expansion of a lignin sulfonate microgel. Journal of Colloid Sciences, vol. 15. pp. 452-471.

RumpF, H. 1962. The strength of granules and agglomerates. Agglomeration. Knepper, W.A. (ed.). Wiley, New York. pp. 379-418.

SHEN, Q., ZHANG, T., and ZHU, M. 2008. A comparison of the surface properties of lignin and sulfonated lignins by FTIR spectroscopy and wicking technique. Colloids and Surfaces A: Physicochemical Engineering, vol. 320. pp. 57-60.

StUART, E., JeRry, D., and Timothy, J. 2001. Lignin. Kirk Othmer Encyclopaedia of Chemical Technology. Wiley, New York, USA. pp. 218-316.

Telysheva, G., Dizhbite, T., and PAegle, E. 2001. Surface active properties of hydrophobized derivatives of lignosulfonates: effect of structure of organosilicon modifier. Journal of Applied Polymer Science. vol. 82. pp. 1013-1020.

VAn DyK, J.C., Keyser, M.J., and CoerTZen, M. 2006. Syngas production from South African coal sources using Sasol-Lurgi gasifiers. International Journal of Coal Geology, vol. 65. pp. 243-253.

XIAO, B., Sun, X.F., and Sun, R. 2001. The chemical modification of lignins with succinic anhydride in aqueous systems. Polymer Degradation and Stability, vol. 71. pp. 223-231.

Zhang, X., Xu, D., Xu, Z., and Cheng. Q, 2001. The effect of different treatment conditions on biomass binder preparation for lignite briquettes. Fuel Processing Technology, vol. 73, no. 3. pp. 185-196.

ZHou, L., ZHu, S., and WANG, X. 2004. The interaction between different CWS dispersants and coals. Journal of Fuel Chemical Technology, vol. 32, no. 4. pp. 400-406. 